\title{
A Systematic Review of COVID-19 Infection in Kidney Transplant Recipients: A Universal Effort to Preserve Patients' Lives and Allografts
}

\author{
Smaragdi Marinaki ${ }^{1}$, Stathis Tsiakas ${ }^{1, *}$, Maria Korogiannou ${ }^{1}$, Konstantinos Grigorakos ${ }^{2}$, \\ Vassilios Papalois ${ }^{3,4}$ and Ioannis Boletis ${ }^{1}$ \\ 1 Clinic of Nephrology and Renal Transplantation, National and Kapodistrian University of Athens Medical \\ School, Laiko Hospital, 11527 Athens, Greece; smaragdimarinaki@yahoo.com (S.M.); \\ mariok_25@yahoo.gr (M.K.); laikneph@laiko.gr (I.B.) \\ 2 Independent Researcher, 12 Protopappa Avenue, 16345 Athens, Greece; gk_pediatr@yahoo.gr \\ 3 Renal and Transplant Directorate, Imperial College Healthcare NHS Trust, London W12 0HS, UK; \\ vassilios.papalois@nhs.net \\ 4 Department of Surgery and Cancer, Imperial College London, London SW7 2AZ, UK \\ * Correspondence: stathis.tsiakas@gmail.com; Tel.: +30-213-206-1151
}

Received: 21 August 2020; Accepted: 10 September 2020; Published: 16 September 2020

\begin{abstract}
The coronavirus disease 2019 (COVID-19) pandemic has posed a significant challenge to physicians and healthcare systems worldwide. Evidence about kidney transplant (KTx) recipients is still limited. A systematic literature review was performed. We included 63 articles published from 1 January until 7 July 2020, reporting on 420 adult KTx recipients with confirmed COVID-19. The mean age of patients was $55 \pm 15$ years. There was a male predominance $(67 \%)$. The majority $(74 \%)$ were deceased donor recipients, and $23 \%$ were recently transplanted ( $<1$ year). Most patients $(88 \%)$ had at least one comorbidity, $29 \%$ had two, and $18 \%$ three. Ninety-three percent of cases were hospitalized. Among them, 30\% were admitted to the intensive care unit, $45 \%$ developed acute respiratory distress syndrome, and $44 \%$ had acute kidney injury with $23 \%$ needing renal replacement therapy. From the hospitalized patients a total of 22\% died, 59\% were discharged, and 19\% were still in hospital at the time of publication. Immunosuppression was reduced in $27 \%$, discontinued in $31 \%$, and remained unchanged in 5\%. Hydroxychloroquine was administered to $78 \%$ of patients, antibiotics to $73 \%$, and antivirals to $30 \%$ while $25 \%$ received corticosteroid boluses, $28 \%$ received anti-interleukin agents, and $8 \%$ were given immunoglobulin. The main finding of our analysis was that the incidence of COVID-19 among kidney transplant patients is not particularly high, but when they do get infected, this is related to significant morbidity and mortality.
\end{abstract}

Keywords: COVID-19 infection; kidney transplantation; outcomes; immunosuppression; treatment

\section{Introduction}

As the first wave of the coronavirus disease 2019 (COVID-19) pandemic is continuing with different effects in different countries, our knowledge about disease features and outcomes of this novel coronavirus in the general population has grown substantially [1].

Kidney transplant (KTx) recipients have been recently classified by the Center for Disease Control and Prevention (CDC) as a high-risk group for severe COVID-19 [2]. Emerging evidence suggests 10-fold higher rates of early case fatality rate (CFR) in transplanted patients compared to that in the general population (GP) [3,4], due to the immunocompromised status resulting in impaired immunological response to pathogens [5] and to the almost universal presence of comorbidities $[6,7]$. 
The body of literature regarding COVID-19 infection in kidney transplantation is growing every day; however, it comprises mostly case reports, small case series, and small cohorts.

There is a broad variation in studies among different countries across the globe. The reported KTx recipients are heterogeneous in terms of race, ethnicity, time from transplantation, and baseline status at the time of COVID-19 infection.

In this systematic review, we analyzed the data of all studies reporting on adult KTx recipients with confirmed COVID-19. We focused on the following: (1) transplant characteristics and patient's baseline status at the time of COVID-19 infection, (2) major outcomes of COVID-19 infection, and (3) therapeutic interventions including modifications of immunosuppression and investigational agents used for COVID-19.

\section{Materials and Methods}

\subsection{Search Strategy}

A systematic search of the literature published from 1 January to 7 July 2020, including PubMed, Web of Science, Scopus, and the Cochrane Library was conducted. The search terms incorporated were: "COVID 19" OR "SARS CoV2" OR "Coronavirus" OR "2019-nCoV" OR "SARS-CoV-2" OR "SARS-CoV" AND "renal" OR "kidney" AND "transplant" OR "transplantation" AND "recipient" OR "patient", using Boolean operators, wildcards, and special characters as described in Supplementary Item S1.

Authors K.G. and S.M. independently reviewed the titles and abstracts for inclusion. This systematic review was conducted in accordance with the Preferred Reported Items for Systematic Reviews and Meta-Analyses (PRISMA 2009) [8], and the flow diagram is depicted in Figure 1. The PRISMA checklist is shown in Supplementary Item S2.

\subsection{Study Selection}

We included the following types of articles: case reports, case series, case-control studies, cohort studies, and correspondence articles. We did not include other systematic reviews, editorials, and conference abstracts. Since almost all studies were observational with small numbers of patients, we included all that were in accordance with our inclusion and exclusion criteria.

According to the P.I.C.O Model for Clinical Questions in Systematic Reviews, our intended patient population $(\mathrm{P})$ comprised all adult (over 18 years old) solid organ transplant recipients who had undergone either kidney transplantation only or multiorgan-including as per definition kidney-transplantation with COVID-19 from 1 January until 7 July 2020. The intervention-exposure (I) was COVID-19 infection confirmed by nucleic acid amplification technique (NAT). We did not have a comparison (C) group. All major adverse outcomes (O) of COVID-19 infection, i.e., hospitalization, intensive care unit (ICU) admission, mechanical ventilation (MV), acute kidney injury (AKI), acute respiratory syndrome (ARDS), and death, were recorded as were recovery and discharge.

\subsection{Data Extraction}

We collected and analyzed the following parameters: last name of the first author, city or region, country, sample size, infection rate, hospitalization, duration of hospitalization (days), ARDS, AKI, ICU admission and duration of stay in ICU, type of MV (invasive and non-invasive), discharge, recovery, death, and case fatality rate (CFR). 


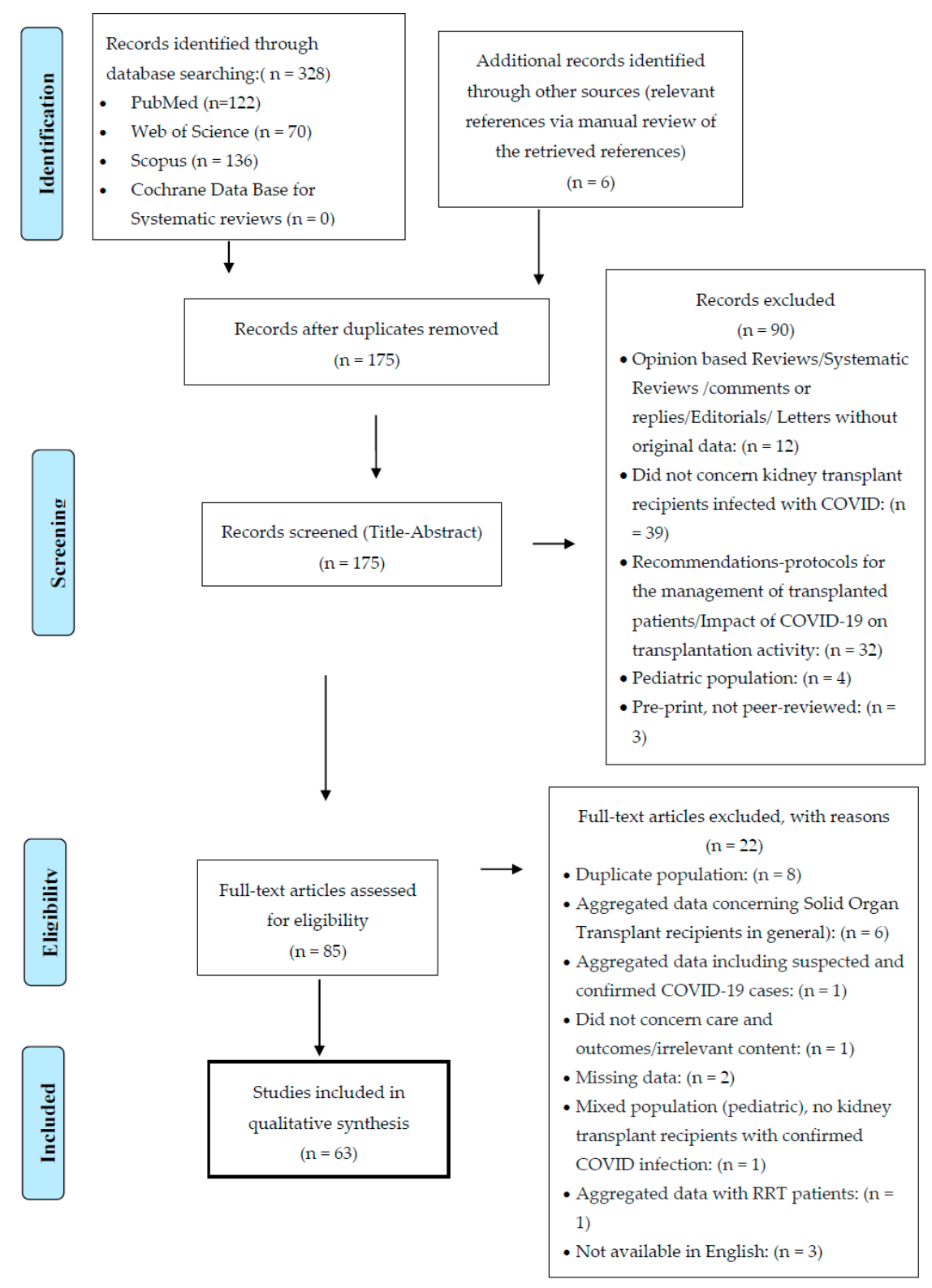

Figure 1. Flow diagram of the systematic literature search according to the Preferred Reported Items for Systematic Reviews and Meta-Analyses (PRISMA) statement. COVID-19: coronavirus disease 2019.

Patients' demographics and baseline characteristics included: age; gender; type of donor: living, deceased, donor after brain death (DBD), donor after cardiac death (DCD); multiple organ transplantation including, as per definition, kidney transplantation; recipient of first, second, or third kidney transplant; time since transplantation. Serum creatinine levels and, if available, estimated glomerular filtration rate (eGFR) were recorded at three time points: baseline at admission, peak during hospitalization, and at discharge. Comorbidities recorded were arterial hypertension (HTN); diabetes mellitus (DM); cardiovascular disease (CVD); malignancy (solid tumors and hematologic malignancies); obesity (OB); chronic obstructive pulmonary disease (COPD); and chronic viral infections including human immunodeficiency virus (HIV), hepatitis B virus (HBV), and hepatitis C virus (HCV).

Baseline immunosuppressive agents and regimens were also recorded, as were modifications in immunosuppression (IS) consisting of discontinuation, reduction, or switch from one agent to another. Induction therapy consisting of anti-interleukin-2 (anti-IL-2) agent basiliximab or antithymocyte globulin (ATG) were recorded in those transplanted for less than one year. 
COVID-19-targeted therapies recorded included: antivirals, hydroxychloroquine (HCQ), antimicrobial agents, corticosteroid boluses, anti-interleukin-6 (anti-IL-6) monoclonal antibodies, interferon (IFN), immunoglobulin, colchicine, and the anti-chemokine-receptor-type 5 (CCR5) inhibitor leronlimab.

\subsection{Statistical Analysis}

We used the Microsoft Office Version 2019 platform to extract, collect, and analyze data. Individual participant data (IPD) were used for all patients reported separately. Aggregated data were also used when information about individual patients with kidney transplantation and confirmed COVID-19 infection was not available. Continuous variables were reported as mean $\pm \mathrm{SD}$ and/or median. Categorical variables were reported as count and percentage.

\section{Results}

\subsection{Overview of Studies}

Our initial search retrieved a total of 328 articles. An additional 6 records were identified through manual screening. After the removal of duplicates, using Endnote Online as citation manager, the remaining 175 studies were screened by title and abstract. Subsequently, 90 articles were removed, based on relevance and inclusion and exclusion criteria. Full-length text was assessed for eligibility in 85 articles. Another 22 studies were excluded due to duplicate or mixed population, aggregated or missing data, and articles in a language other than English.

Finally, 63 articles reporting on 420 KTx recipients with confirmed COVID-19 infection were included. There were 28 case reports, 14 case series, 1 case-control study, 1 cohort study, and 19 correspondence articles from a total of 18 countries (Table 1; Table 2).

Table 1. Studies included in the analysis (Case Reports)

\begin{tabular}{ccccc}
\hline & & & & \\
\hline Authors & Region/Country & Patients (No.) & Type of Study & Hospitalized \\
\hline [9] Akdur et al. & Ankara, Turkey & 1 & Case Report & 0 \\
[10] Allam et al. & Fort Worth, TX, USA & 1 & Correspondence & 1 \\
[11] Bartiromo et al. & Florence, Italy & 1 & Correspondence & 1 \\
[12] Billah et al. & New York, NY, USA & 1 & Correspondence & 1 \\
[13] Bussalino et al. & Genoa, Italy & 1 & Case Report & 1 \\
[14] Chen et al. & Wuhan, China & 1 & Case Report & 1 \\
[15] Cheng et al. & Nanjing, China & 2 & Case Report & 2 \\
[16] Chenna et al. & Albany, NY, USA & 1 & Case Report & 1 \\
[17] Dirim et al. & Istanbul, Turkey & 1 & Case Report & 1 \\
[18] Fontana et al. & Modena, Italy & 1 & Case Report & 1 \\
[19] Gandolfini et al. & Parma, Italy & 2 & Correspondence & 2 \\
[20] Guillen et al. & Barcelona, Spain & 1 & Case Report & 1 \\
[21] Hasan Ahmad et al. & Ipswich, UK. & 1 & Correspondence & 1 \\
[22] Hsu et al. & Los Angeles, CA, USA & 1 & Case Report & 1 \\
[23] Huang et al. & Fuzhou, China & 1 & Case Report & 1 \\
[24] Jiang et al. & Wuhan, China & 1 & Correspondence & 1 \\
[25] Kates et al. & Seattle, WA, USA & 1 & Case Report & 1 \\
[26] Kemmner et al. & Munich, Germany & 1 & Correspondence & 1 \\
[27] Kim et al. & Daegu, Korea & 2 & Case Report & 2 \\
[28] Kocak et al. & Istanbul, Turkey & 2 & Case Report & 2 \\
[29] Kolonko et al. & Katowice, Poland & 3 & Case Report & 3 \\
[30] Kumar et al. & Chicago, IL, USA & 1 & Case Report & 0 \\
[31] Lauterio et al. & Milan, Italy & 1 & Correspondence & 1 \\
[32] Machado et al. & Sao Paulo, Brazil & 1 & Case Report & 1 \\
[33] Man et al. & Wuhan, China & 1 & Correspondence & 1 \\
[34] Marx et al. & Strasbourg, France & 1 & Correspondence & 1 \\
\hline
\end{tabular}


Table 1. Cont.

\begin{tabular}{ccccc}
\hline \multicolumn{4}{c}{ Case Reports } \\
\hline Authors & Region/Country & Patients (No.) & Type of Study & Hospitalized \\
\hline [35] Meziyerh et al. & Leiden, Netherlands & 1 & Case Report & 1 \\
[36] Namazee et al. & Semnan, Iran & 1 & Case Report & 1 \\
[37] Ning et al. & Hefei, China & 1 & Case Report & 1 \\
[38] Seminari et al. & Pavia, Italy & 1 & Case Report & 1 \\
[39] Serrano et al. & Hartford, CT, USA & 1 & Case Report & 1 \\
[40] Shingare et al. & Mumbai, India & 2 & Case Report & 2 \\
[41] SJ Antony et al. & El Paso, TX, USA & 1 & Case Report & 1 \\
[42] Suwanwongse et al. & New York, NY, USA & 1 & Case Report & 1 \\
[43] Tantisattamo et al. & Orange, CA, USA & 1 & Case Report & 1 \\
[44] Thammathiwat et al. & Bangkok, Thailand & 1 & Case Report & 1 \\
[45] Velioglu et al. & Istanbul, Turkey & 1 & Correspondence & 0 \\
[46] Wang et al. & Zhengzhou, China & 1 & Correspondence & 1 \\
[47] Xia et al. & Wuhan, China & 1 & Correspondence & 1 \\
[48] Xu et al. & Ottawa, Canada & 1 & Case Report & 1 \\
[49] Zhong et al. & Wuhan, China & 1 & Case Report & 1 \\
\hline
\end{tabular}

Table 2. Studies included in the analysis (Case Series)

\begin{tabular}{|c|c|c|c|c|c|c|}
\hline \multicolumn{7}{|c|}{ Case Series } \\
\hline Authors & Region/Country & Patients (No) & Type of Study & Hospitalized & Infection Rate (\%) & CFR (\%) \\
\hline [50] Abrishami et al. & Tehran, Iran & 12 & Case Series & 12 & - & 66.7 \\
\hline [3] Akalin et al. & Bronx, NY, USA & 36 & Correspondence & 28 & - & 27.8 \\
\hline [7] Alberici et al. & Brescia, Italy & 20 & Case Series & 20 & 1.67 & 25 \\
\hline [51] Banerjee et al. & London, UK. & 7 & Case Series & 5 & - & - \\
\hline [52] Bosch et al. & Munich, Germany & 3 & Case Series & 3 & - & - \\
\hline [53] Bossini et al. & Brescia, Italy & 53 & Case Series & 45 & - & 28.3 \\
\hline [54] Chen et al. & Brooklyn, NY, USA & 30 & Case Series & 30 & - & 20 \\
\hline [55] Columbia University & New York, NY, USA & 15 & Case Series & 15 & - & 13.3 \\
\hline [56] Crespo et al. & Barcelona, Spain & 16 & Correspondence & 15 & 4.93 & 50 \\
\hline [57] Devresse et al. & Brussels, Belgium & 22 & Case Series & 18 & 1.83 & 9.1 \\
\hline [58] Fernandez-Ruiz et al. & Madrid, Spain & 8 & Correspondence & 8 & - & - \\
\hline [59] Fung et al. & San Francisco, CA, USA & 7 & Case Series & 5 & - & - \\
\hline [60] Maritati et al. & Ancona, Italy & 5 & Case Series & 5 & - & 25 \\
\hline [61] Mehta et al. & New York, NY, USA & 34 & Correspondence & 34 & - & 17.1 \\
\hline [62] Mella et al. & Turin, Italy & 6 & Case Series & 6 & - & - \\
\hline [63] Montagud-Marrahi et al. & Barcelona, Spain & 33 & Correspondence & 26 & - & 6 \\
\hline [6] Nair et al. & Hempstead, NY, USA & 10 & Case Series & 9 & - & 33.3 \\
\hline [64] Rodriguez-Cubillo et al. & Madrid, Spain & 29 & Correspondence & 29 & - & 20.7 \\
\hline [65] Silva et al. & Porto, Portugal & 5 & Case Series & 4 & - & - \\
\hline [66] Trujillo et al. & Madrid, Spain & 26 & Case Series & 26 & 1.04 & 23.1 \\
\hline [67] Zhang et al. & Wuhan, China & 5 & Case Series & 5 & - & - \\
\hline [68] Zhu et al. & Wuhan, China & 10 & Case-control Study & 10 & 0.33 & 10 \\
\hline
\end{tabular}

CFR: case fatality rate

There were 142 patients from the U.S., 113 from Spain, 71 from Italy, 25 from China, 22 from Belgium, 13 from Iran, 8 from the U.K., 5 from Turkey, 5 from Portugal, 4 from Germany, 3 from Poland, 2 from Korea, and 1 each from the Netherlands, France, Canada, Brazil, and Thailand, respectively.

For identification of the risk of bias, authors S.M. and K.G. independently performed a quality assessment of 63 studies. In case of disagreement, the problem was solved by discussion. The quality of case series included was assessed using the Joanna Briggs Institute's (JBI) critical appraisal checklist for case series, which consists of 9 quality items. Studies with up to 4 positive responses were considered to have low quality, while those with 5 to 9 positive responses had high quality. The study quality of case reports was assessed with the JBI checklist for case reports. The range of the JBI scale is between 0 and 8 , with a score of 0-3 denoting low quality and 4-8 denoting high quality. Accordingly, all studies were included in the analysis. The risk of bias assessment is shown in Supplementary Items S3 and S4. 
3.2. Demographic and Baseline Characteristics, Clinical Outcomes, and Treatment of Kidney Transplant Recipients with COVID-19 Infection

\subsubsection{Patients' Demographics and Baseline Characteristics}

The mean and median age of the 169 patients for whom IPD were available were $55 \pm 15$ years and 55 years (range 21-80) respectively. The reported median age from available aggregated data ranged from 57 to 60 years. There was a male predominance of $67 \%$.

The majority of KTx recipients $(74 \%)$ had received a deceased donor transplant (DBD in $95 \%$ of cases), while $26 \%$ had been transplanted from a living donor. In 156 cases, the donor source was not reported.

Seven out of 420 patients (2\%) were multiple organ transplant recipients: 2 received liver and kidney, 2 received heart and kidney, and 3 received pancreas and kidney, respectively.

From the total cohort, only $2 \%$ patients had undergone subsequent kidney transplantations. Median time from KTx to COVID-19 infection was 6.5 years (range $0-33$ ) while $23 \%$ of the patients were transplanted for less than one year.

The majority of patients ( $81 \%$ ) suffered from HTN, while only $12 \%$ had no comorbidities. The second most frequent associated medical condition was DM (36\%), followed by CVD $(21 \%)$, OB $(15 \%)$, COPD (5\%), malignancy (4\%), and chronic viral infection ( $2 \%)$.

Out of 162 patients with comorbidities, $41 \%$ had one, $29 \%$ had two, and $18 \%$ suffered from three comorbidities.

Baseline renal function was relatively well-preserved with a median serum creatinine of $1.47 \mathrm{mg} / \mathrm{dL}$ in 91 patients. Baseline eGFR was assessed in few studies (16 out of 63) with a mean of $40 \pm 23 \mathrm{~mL} / \mathrm{min} / 1.73 \mathrm{~m}^{2}$. Median peak serum creatinine during hospitalization was $2.2 \mathrm{mg} / \mathrm{dL}$ (range $0.62-10.94$ ) and returned to $1.4 \mathrm{mg} / \mathrm{dL}$ at discharge.

The patients' clinical features and outcome as well as management strategies are depicted in Table 3.

Table 3. Demographic and baseline characteristics, clinical outcomes, and treatment of kidney transplant recipients with coronavirus disease 2019 (COVID-19) infection.

\begin{tabular}{cc}
\hline Demographics & \\
\hline Age (years, median) $(n=169)$ & $55(21-80)$ \\
Gender (male) & $276 / 415(67 \%)$ \\
Type of donor (deceased donor) & $195 / 264(74 \%)$ \\
Multiple organ transplant recipients & $7 / 420(2 \%)$ \\
Repeat KTx & $7 / 420(2 \%)$ \\
Time from KTx (years, median) & $6.5(0-33)$ \\
Time from KTx $\leq 1$ year & $48 / 209(23 \%)$ \\
Comorbidities $(n=326)$ & \\
HTN & $81 \%$ \\
DM & $36 \%$ \\
Obesity & $21 \%$ \\
COPD & $15 \%$ \\
Malignancy & $5 \%$ \\
Chronic viral infection & $4 \%$ \\
Renal function & $2 \%$ \\
Baseline sCr (mg/dL, median) $(n=91)$ & $1.47(0.62-5.09)$ \\
sCr at discharge (median) $(n=58)$ & $2.17(0.62-10.94)$ \\
Baseline Immunosuppressive regimen & $1.45(0.29-6.45)$ \\
MPA/AZA + CNI \pm CS & \\
Hospital admission $(n=420)$ & $136 / 186(73 \%)$ \\
Admission to ICU & $93 \%$ \\
Duration of hospitalization (days, median) $(n=104)$ & $16(1-100)$ \\
Duration of ICU stay (days, median) $(n=32)$ & $8.5(1-34)$ \\
\hline during hospitalization (mg/dL, median) & \\
\hline
\end{tabular}


Table 3. Cont.

\begin{tabular}{|c|c|}
\hline Demographics & \\
\hline \multicolumn{2}{|l|}{ Type of Ventilation } \\
\hline NIV & $27 / 379(7 \%)$ \\
\hline IMV & $88 / 379(23 \%)$ \\
\hline ARDS & $175 / 391(45 \%)$ \\
\hline AKI & $150 / 345(44 \%)$ \\
\hline RRT & $34 / 150(23 \%)$ \\
\hline \multicolumn{2}{|l|}{ Immunosuppression management } \\
\hline IS discontinuation & $66 / 212(31 \%)$ \\
\hline IS reduction & $97 / 357(27 \%)$ \\
\hline Switch TAC or mTORi to CsA & $24 / 358(7 \%)$ \\
\hline CNI tapering & $65 / 204(32 \%)$ \\
\hline CNI withdrawal & $118 / 204(58 \%)$ \\
\hline Antimetabolite withdrawal & $227 / 250(91 \%)$ \\
\hline \multicolumn{2}{|l|}{ COVID-19 treatment } \\
\hline Antivirals & $123 / 414(30 \%)$ \\
\hline Lopinavir/Ritonavir & $94 / 123(76 \%)$ \\
\hline HCQ & $320 / 409(78 \%)$ \\
\hline Antibiotics & $290 / 399(73 \%)$ \\
\hline Azithromycin & $155 / 290(53 \%)$ \\
\hline CS (IV bolus or Dexamethasone) & $83 / 331(25 \%)$ \\
\hline Anti-IL agents & $59 / 213(28 \%)$ \\
\hline IV immunoglobulins & $35 / 415(8 \%)$ \\
\hline \multicolumn{2}{|l|}{ Major outcomes } \\
\hline Death & $93 / 420(22 \%)$ \\
\hline Discharge & $232 / 391(59 \%)$ \\
\hline
\end{tabular}

Data are presented as the number/total number of available observations (percent) unless otherwise stated. Abbreviations: AKI: acute kidney injury; ARDS: acute respiratory distress syndrome; AZA: azathioprine; CNI: calcineurin inhibitor; COPD: chronic obstructive pulmonary disease; COVID-19: Coronavirus disease 2019; CS: corticosteroids; CsA: cyclosporine; CVD: cardiovascular disease; DM: diabetes mellitus; HCQ: hydroxychloroquine; HTN: hypertension; ICU: intensive care unit; IL: interleukin; IMV: invasive mechanical ventilation; IS: immunosuppression; IV: intravenous; KTx: kidney transplantation; MPA: mycophenolic acid; mTORi: mammalian target of rapamycin inhibitor; n: number; NIV: non-invasive ventilation; RRT: renal replacement therapy; sCr: serum creatinine; TAC: tacrolimus.

\subsubsection{Major Clinical Outcomes after COVID-19 Infection}

Infection rate in our study ranged from $0.27 \%$ to $1.67 \%$ and was calculated in those studies where the number of the total cohort of KTx recipients was available.

From the total cohort, $93 \%$ of patients were hospitalized. Median duration of hospitalization was 16 days (range 1-100). From 391 hospitalized patients, 118 (30\%) were admitted to the ICU. In 32 out of 118 patients, the median duration of the ICU stay was 8.5 days (range 1-34). Non-invasive mechanical ventilation (NIV) was applied to $7 \%$ and invasive mechanical ventilation (IMV) to $23 \%$ of patients. ARDS was reported in (175/391) 45\% of patients. A substantial proportion of patients, (150/345) $44 \%$ developed AKI, with need for renal replacement therapy (RRT) reported in $23 \%$. Death was recorded in (93/420) $22 \%$ of patients. Most patients, (232/391) 59\% were discharged; 29 patients remained hospitalized when the studies were published, 14 of whom were still in the ICU.

Case fatality rates in the case series including more than ten patients ranged from $6 \%$ up to $67 \%$.

\subsubsection{Baseline Immunosuppression and Modifications during COVID-19 Infection}

The most frequently applied immunosuppressive regimen at baseline consisted of a calcineurin inhibitor (CNI), an antimetabolite, and corticosteroids (CS) in $73 \%$ of patients.

In total, $64 \%$ (147/230) of patients were receiving tacrolimus (TAC), 10\% (18/176) cyclosporine (CsA), 68\% (217/319) mycophenolic acid (MPA), 14\% (26/184) everolimus, 4\% (9/211) azathioprine (AZA), and a minority $(<2 \%)$ of patients other agents such as belatacept, mizoribine, or leflunomide. 
Overall, IS was reduced in 27\% (97/357), discontinued in 31\% (66/212), and remained unchanged in $5 \%(14 / 275)$ of patients. The most frequently discontinued drug was the antimetabolite in $91 \%(227 / 250)$ of patients. Calcineurin inhibitors were reduced in 32\% (65/204) and discontinued in 58\% (118/204) of patients. Switch from TAC or mammalian target of rapamycin inhibitor (mTORi) to CsA occurred in $7 \%(24 / 358)$ of patients. The mTORi was reduced in $7 \%(2 / 27)$ and discontinued in $67 \%(18 / 27)$ of cases.

\subsubsection{COVID-19-Targeted Therapies}

The main agents used for COVID-19 infection were antivirals, antibiotics, hydroxychloroquine (HCQ), anti-IL monoclonal antibodies, and steroid boluses.

In total, 30\% (123/414) of patients received antivirals. The most frequently used antiviral was lopinavir/ ritonavir, administered to $76 \%(94 / 123)$ of those. Other antivirals included darunavir/ritonavir (13\%), ritonavir-darunavir/lopinavir (4\%), oseltamivir or arbidol (11\%), umifenovir $(7 \%)$, and darunavir/cobicistat $(2 \%)$.

Hydroxychloroquine was administered to $78 \%$ (320/409) of patients.

The majority of patients $(73 \%, 290 / 399)$ received antibiotics: azithromycin was administered to $53 \%(155 / 290)$ and other broad-spectrum antibiotics to $17 \%$ (50/290) of cases.

Corticosteroid (CS) boluses or dexamethasone were used in 25\% (83/331) of patients.

Anti-IL agents were introduced in $28 \%$ (59/213) of patients with more severe illness; tocilizumab was the preferred agent in 56 of 59 patients.

Less frequently used agents were immunoglobulin in $8 \%$, colchicine in $0.5 \%$, interferon in $0.5 \%$, and leronlimab in $1.4 \%$ of patients.

\subsection{Subgroup Analysis}

We separately investigated three patient groups: recent transplanted recipients, elderly patients, and those who died. Outcomes are depicted in Table 4.

Table 4. Demographic and baseline characteristics, treatment, and clinical outcomes of specific subgroups of kidney transplant recipients with COVID-19 infection.

\begin{tabular}{cc}
\hline \multicolumn{2}{c}{ Characteristics of Patients with KTx for $\leq \mathbf{1}$ year } \\
\hline Age (years, mean \pm SD) $(n=29)$ & $53.9 \pm 13.9$ \\
Gender (male) & $18 / 34(53 \%)$ \\
Baseline sCr $(\mathrm{mg} / \mathrm{dL}$, median) $(n=21)$ & $1.24(0.75-2.7)$ \\
Induction immunosuppression $(n=17)$ & \\
Antithymocyte globulin (ATG) & $8 / 17(47 \%)$ \\
Basiliximab & $1 / 17(6 \%)$ \\
Baseline Immunosuppression $(n=34)$ & \\
MPA + CNI \pm CS & $31 / 34(91.2 \%)$ \\
IS discontinuation & $9 / 34(27 \%)$ \\
IS reduction & $18 / 34(53 \%)$ \\
Antimetabolite withdrawal & $26 / 34(77 \%)$ \\
COVID-19 Treatment & \\
Antivirals & $7 / 34(21 \%)$ \\
HCQ & $18 / 32(56 \%)$ \\
Azithromycin & $3 / 32(9 \%)$ \\
Corticosteroids (IV) & $3 / 32(9 \%)$ \\
Tocilizumab & $3 / 32(9 \%)$ \\
Hospital admission & $32 / 34(94 \%)$ \\
Admission to ICU & $9 / 32(28 \%)$ \\
ARDS & $10 / 32(31 \%)$ \\
AKI & $12 / 32(38 \%)$ \\
Death & $5 / 34(15 \%)$ \\
\hline &
\end{tabular}


Table 4. Cont.

\begin{tabular}{|c|c|}
\hline Characteristics of patients $\geq 65$ years & \\
\hline Age (years, mean \pm SD) $(n=54)$ & $71.6 \pm 4.7$ \\
\hline Gender (male) & $45 / 70(64 \%)$ \\
\hline Baseline $\mathrm{sCr}(\mathrm{mg} / \mathrm{dL}$, median $)(n=23)$ & $1.8(0.62-3.39)$ \\
\hline \multicolumn{2}{|l|}{ Baseline Immunosuppression $(n=52)$} \\
\hline $\mathrm{MPA} / \mathrm{AZA}+\mathrm{CNI} \pm \mathrm{CS}$ & $34 / 52(65 \%)$ \\
\hline mTORi-based regimen & $9 / 52(17 \%)$ \\
\hline IS discontinuation & $28 / 54(52 \%)$ \\
\hline IS reduction & $17 / 54(32 \%)$ \\
\hline \multicolumn{2}{|l|}{ COVID-19 Treatment } \\
\hline Antivirals & $19 / 69(28 \%)$ \\
\hline HCQ & $53 / 70(76 \%)$ \\
\hline Azithromycin & $19 / 63(30 \%)$ \\
\hline Corticosteroids (IV) & $18 / 70(26 \%)$ \\
\hline Tocilizumab & $11 / 70(16 \%)$ \\
\hline Hospital admission & $69 / 70(99 \%)$ \\
\hline Admission to ICU & $13 / 69(19 \%)$ \\
\hline ARDS & $32 / 69(46 \%)$ \\
\hline AKI & $24 / 68(35 \%)$ \\
\hline Death & $22 / 69(32 \%)$ \\
\hline \multicolumn{2}{|l|}{ Characteristics of patients who died } \\
\hline Age (years, mean $\pm \mathrm{SD})(n=37)$ & $64.2 \pm 9.1$ \\
\hline Gender (male) & $37 / 61(61 \%)$ \\
\hline Baseline $\mathrm{sCr}(\mathrm{mg} / \mathrm{dL}$, mean $\pm \mathrm{SD})(n=20)$ & $2.14 \pm 0.9$ \\
\hline IS discontinuation & $36 / 65(55 \%)$ \\
\hline IS reduction & $18 / 51(35 \%)$ \\
\hline \multicolumn{2}{|l|}{ COVID-19 Treatment } \\
\hline Antivirals & $26 / 79(33 \%)$ \\
\hline HCQ & $51 / 64(80 \%)$ \\
\hline Azithromycin & $19 / 54(35 \%)$ \\
\hline Corticosteroids (IV) & $32 / 74(43 \%)$ \\
\hline Tocilizumab & $15 / 74(20 \%)$ \\
\hline Admission to ICU & $47 / 81(58 \%)$ \\
\hline ARDS & $62 / 77(81 \%)$ \\
\hline AKI & $26 / 45(58 \%)$ \\
\hline
\end{tabular}

Data are presented as the number/total number of available observations (percent) unless otherwise stated. Abbreviations: ATG: antithymocyte globulin.

\section{Discussion}

In this review, we focused on the baseline status of the patients at the time of acquiring the infection, on the major clinical outcomes, as well as on the therapeutic interventions.

\subsection{Infection Rates}

Emerging evidence suggests that kidney transplant recipients are not at particularly high risk of acquiring the infection. Infection rates in our review range from $0.27 \%$ to $1.67 \%$, with the highest rate of $5 \%$ reported in a study from Spain [56], in a cohort of elderly ( $>65$ years) recipients. Of note, the infection rate among younger recipients in the same cohort was at $0.8 \%$. However, infection rates depend greatly on the number of tested individuals; therefore, it is impossible to draw definite conclusions.

\subsection{Clinical Presentation}

Most agree that presenting symptoms are similar to those of non-transplanted patients with fever $(85 \%)$, dry cough $(70 \%)$, myalgia $(60 \%)$, and dyspnea $(57 \%)$ being the most frequently reported symptoms $[6,69]$. 
In a substantial number of transplanted patients, mild and/or atypical initial presentation with less fever and dyspnea and predominantly gastrointestinal symptoms has been reported $[3,20,64,68,70]$, suggesting need for increased vigilance.

\subsection{Disease Course}

Illness severity at presentation among KTx recipients may vary significantly, similar to the case in the general population. However, acute respiratory decompensation and rapid clinical deterioration have been described in hospitalized as well as outpatient KTx recipients at an average of 7-10 days after disease onset. $[3,7,53,61,71]$. Though the management of KTx recipients with mild symptoms as outpatients may be a reasonable option, given the lack of prognostic indicators for eventual deterioration and current evidence about acute decompensation, rapid testing and early hospitalization is advisable.

\subsection{Disease Severity}

The initial suggestion that an immunocompromised status would hypothetically limit a striking cytokine release and lead to a milder disease course [72] has been confuted by current evidence. On the contrary, kidney Tx recipients acquiring COVID-19 infection are at high risk of developing severe disease due in fact to their immunocompromised status.

The presence of at least one comorbidity is an almost universal finding in transplanted patients. In non-transplanted individuals, comorbidities have been associated with adverse COVID-19 outcomes [73].

\subsection{Baseline Status of Kidney Transplant Recipients}

The mean age of the KTx recipients was $55 \pm 15$ years, and they were predominantly male.

Regarding transplantation parameters, most patients were deceased donor recipients. Time from transplantation to COVID-19 infection varied greatly: median 6.5, range 0-33 years. Only 23\% were recently transplanted.

Renal function at baseline was relatively well-preserved: mean serum creatinine was $1.68 \pm 0.77 \mathrm{mg} / \mathrm{dL}$ and mean eGFR $39.7 \pm 23 \mathrm{~mL} / \mathrm{min} / 1.73 \mathrm{~m}^{2}$.

\subsection{Comorbidities}

Our analysis confirmed the almost universal presence of at least one comorbidity in the KTx population: HTN was the most prevalent in $81 \%$ of patients, followed by DM in $36 \%$, CVD in $21 \%$, obesity in $15 \%$, and COPD in 5\%. Remarkably, a substantial proportion (29\%) of patients suffered from two and another $18 \%$ from three comorbidities. Hypertension, diabetes, CVD, and COPD have been identified early during the COVID-19 outbreak as risk factors for adverse outcomes [74]. African-American race as well as obesity have been recently associated with more severe COVID-19 [74,75].

\subsection{Major Outcomes}

All major adverse clinical outcomes related to COVID-19 including death were more prevalent in KTx recipients [76]. We found a hospitalization rate of $93 \%$. This may include a selection bias, since indeed most studies reported those patients who had the most severe disease course and were hospitalized. We also found prolonged hospital stay (median 16 days) and a high ICU admission rate of $30 \%$ among them.

A total of $30 \%$ of KTx recipients needed mechanical ventilation: $23 \%$ invasive (IMV) and another $7 \%$ required non-invasive mechanical ventilation (NIV) support, while $45 \%$ of KTx developed ARDS.

We found a high rate of AKI in $44 \%$ of KTx recipients, compared to $29 \%$ in critically ill COVID-19-infected patients of the GP and to $15 \%$ in COVID-infected patients in general [77]. A substantial proportion of those developing AKI in our study (23\%) needed RRT. AKI was reversible 
in most cases who recovered. Regarding the etiology of AKI, direct damage of the proximal tubular epithelial cells by the severe acute respiratory syndrome coronavirus 2 (SARS-CoV-2) has been reported early during the outbreak [78] but could not be confirmed later on. AKI as a result of renal damage due to uncontrolled cytokine storm seems to be currently the most prevalent theory [79]. Furthermore, in a kidney transplant recipient, IS reduction or withdrawal may lead to acute allograft rejection. No renal biopsy was reported in any of the 420 analyzed recipients. In the absence of biopsy confirmation and given the fact that AKI resolved in most of them who recovered, the most plausible explanation is the occurrence of AKI in the setting of multiorgan failure in patients with a sole functioning kidney and preexisting chronic kidney disease (CKD).

The overall death rate in our analysis was $22 \%$.

In 13 case series including more than 10 patients, CFR ranged from $6 \%$ up to $67 \%$. The highest CFR was reported by Nair (U.S., 33\%), Crespo (Spain, 50\%), Abrishami (Iran, 67\%), Akalin (U.S., 28\%), and Bossini (Italy, 28\%) [3,6,50,53,56].

Nair [6] and Akalin [3] reported on 10 and 36 KTx recipients from NY city with CFRs of 33\% and $28 \%$, respectively. The small numbers of patients, the racial diversity, and the fact that the reports come from the epicenter of the pandemic in the U.S., are all factors that may have contributed to the high CFR in this series.

The study by Crespo et al. [56] reports a CFR of 50\% in a selected cohort of 16 transplanted patients with confirmed COVID-19 infection who were all above 65 years. Older age is a known risk factor for adverse outcomes in patients with COVID-19. Further risk factors in this cohort included frailty, obesity, and underlying heart disease.

Abrishami et al. [50] from Iran, reports a CFR of $67 \%$ in a cohort of predominantly young patients with well-preserved renal function and few comorbidities. There is no obvious cause for this inexplicably high CFR in this study.

In a recent study, Bossini and Alberici [53] analyzed $53 \mathrm{KTx}$ recipients from Italy, 45 of whom were hospitalized. The CFR was $33 \%$ in hospitalized patients and $28 \%$ in the entire cohort also including outpatients.

At this point, it is important to underline the high rates of adverse outcomes associated with COVID-19 infection in KTx recipients. Compared to the outcomes of influenza in solid organ transplant (SOT) recipients, as described in a review by Mombelli et al. [80], all adverse outcomes were higher in those with COVID-19 infection: $93 \%$ vs. 70\% hospitalization rate and 30\% vs. $16 \%$ ICU admission, respectively. The most striking difference was in early CFR: $22 \%$ vs. $3-8 \%$.

\subsection{Modifications in Immunosuppression}

Managing IS in a KTx recipient in the context of severe infection is a complex approach. Since immunological response to infections is reduced in immunocompromised hosts, there is rationale to reduce and even to temporarily withdraw IS in case of severe COVID-19 disease. One has to balance the benefit of at least partially "restoring" the immune response in order to save the patient's life against the risk of losing the graft due to acute rejection.

In our analysis, there was a high rate of IS reduction or withdrawal. Total IS was reduced in $27 \%$ and completely withdrawn, with the exception of steroids, in another $31 \%$ of patients.

The antimetabolites should be discontinued first because of their effect on inhibiting T-cell function and proliferation [81]. We found a rate of antimetabolite discontinuation of $91 \%$.

Though mTOR-inhibitors have antiviral potential [82], they have been associated with various types of lung injury [83] and should preferentially also be withdrawn. In our study, the rate of mTORi reduction was $7 \%$ and the rate of withdrawal $67 \%$.

Regarding CNIs, the most common approach is to minimize doses, which has proven efficacy in severe viral or opportunistic infections [5]. CNIs were withdrawn in $58 \%$ and reduced in $32 \%$ of cases in our study. Specifically, for cyclosporine, there are in vitro studies demonstrating that CsA suppresses viral replication through the inhibition of cyclophilin and this effect could be also demonstrated for 
the virus SARS-CoV-2. Based on this theoretical benefit and with the fear of completely withdrawing IS, another approach is to switch the tacrolimus or mTORi-based regimen to CsA, which occurred in $7 \%$ of cases in our study.

As for corticosteroids, since all practices including withdrawal, reintroduction, dose reduction, maintenance or increase, switch from oral to intravenous, or administration of boluses had been applied, we recorded only patients who had taken boluses as discussed in the next section.

\subsection{COVID-Targeted Therapies}

The main pharmacological interventions for the treatment of COVID-19 infection included antivirals in $30 \%$ of patients, broad-spectrum antibiotics in $73 \%$, hydroxychloroquine in $78 \%$, tocilizumab in $26 \%$, steroid boluses in $25 \%$, and less frequently other anti-IL agents (Clazakizumab, Anakinra), colchicine, immunoglobulin, interferon, and the anti-CCR5, leronlimab.

From the $30 \%$ of KTx patients who received antivirals, the majority, $76 \%$ received the combination of protease inhibitors lopinavir/ritonavir. They interact with CNIs by dramatically increasing their levels and prolonging half-lives; if used concomitantly with CNIs, drastic dose reduction and prolonged dosing intervals of the CNI are mandatory, otherwise patients will be exposed to prolonged overimmunosuppression, with detrimental effects in critically ill individuals [84]. The safest approach is to completely withdraw CNIs if they are co-administered. Moreover, they induce QT prolongation which, especially in combination with HCQ or azithromycin, is additive and may lead to severe arrhythmia [85].

Remdesivir is a nucleotide analogue initially developed to treat Ebola virus [86]. It has not been used until the outbreak of the COVID-19 pandemic but has shown efficacy in the GP [87].

Regarding hydroxychloroquine, early reports suggested a role in reducing the viral load [88]. Since it is cheap and easily available, it has been applied broadly. In total, 78\% of KTx recipients received HCQ. Current data do not further support the use of lopinavir/ritonavir and HCQ in hospitalized patients with COVID-19 infection. On July 4, the World Health Organization (WHO) announced the discontinuation of the two treatment arms (HCQ/Lop-Riton) of the SOLIDARITY Trial based on results of the interim analysis that showed no effect in terms of reducing mortality [89].

Corticosteroid boluses have been used in $25 \%$ of KTx recipients. Since they increase viral replication, they are not desirable at the first phase of COVID-19 infection. In critically ill patients, they have immunomodulatory effects [90]. Steroid boluses are recommended for patients with ARDS; furthermore, the RECOVERY trial has shown benefit of high doses of dexamethasone in patients under mechanical ventilation [91]. The most reasonable approach is to maintain the lowest possible CS doses in the first phase of the infection and to administer boluses in those who develop severe illness.

Since severe COVID-19 infection has been associated with a cytokine storm [92], there is rationale for the use of anti-IL agents. Monoclonal antibodies that inhibit cytokines were used in $28 \%$ of KTx recipients in our study. The most commonly used was the IL-6 receptor antagonist tocilizumab in $26 \%$ of them. Less frequently applied agents included clazakizumab, anakinra, and leronlimab.

Unfortunately, due to the small numbers of patients in the studies investigated, the different time points during the disease course at which therapies were applied, and the different time points at which studies have been published, it is impossible to draw conclusions about the impact of therapeutic interventions on outcomes.

\subsection{Subgroup Analysis}

Three patient groups, i.e., recent transplanted recipients, elderly patients, and those who died, were analyzed separately.

A total of $23 \%$ with available IPD were recent KTx recipients. They did not differ from the total cohort in means of baseline characteristics, with the exception of better renal function. In terms of outcomes, though nearly half of them had received ATG, they had lower rates of AKI ( $38 \%$ vs. $44 \%$ ), 
ARDS ( $31 \%$ vs. $45 \%)$, and death ( $15 \%$ vs. $22 \%$ ) compared to those in the entire cohort. This finding further confirms preliminary data suggesting at least not worse outcomes in this subgroup of KTx recipients.

Patients older than 65 analyzed, comprised 34\% of those for whom information was available. Only $4 \%$ had no comorbidity vs. $12 \%$ in the total cohort, while baseline creatinine was higher, at $1.8 \mathrm{mg} / \mathrm{dL}$. A substantial proportion (17\%) of them were on mTORi-based IS at baseline. The ICU admission rate was $19 \%$ vs. $30 \%$ in the total population, indicating either healthcare resource unavailability or decision not to intervene due to frailty and comorbidities. The death rate was higher at $32 \%$ vs. $22 \%$.

Those who died (93 out of 420) were older: 27 out of 55 were over 65 years and predominantly male $(61 \%)$, and they had worse baseline renal function. All adverse outcome rates were strikingly higher: ICU admission at $58 \%, 62 \%$ had need for invasive mechanical ventilation support, $81 \%$ developed ARDS, and $58 \%$ had AKI. In terms of therapeutic intervention, they had higher rates of intravenous CS $(43 \%)$ but not of tocilizumab (20\%) administration.

\subsection{Limitations and Need for Future Research}

The major limitation of our analysis was that the included articles were case reports and case series, which are subject to selection and publication bias. Thus, it is uncertain whether the results of our systematic review can be extrapolated to the general KTx-recipient population. There were a limited number of patients from all over the globe with a broad diversity in terms of race, ethnicity, and country of origin, as well as transplant and clinical characteristics. Besides patients' heterogeneity, there is also variation in outcomes, disease course, and management of transplanted patients described, according to the time of publication of the study. Moreover, therapeutic interventions varied among countries depending on local policies, ethical issues, and healthcare resource availability conjointly with the "total COVID-disease burden" of the specific country. Thus, we could perform only descriptive statistics, and no conclusion could be drawn about the impact of therapeutic interventions on outcomes.

In view of the absence of a commercially available vaccine in the near future and given the fact that COVID-19 is our new reality, especially for vulnerable patient groups such as KTx recipients, large registry data and targeted studies assessing the impact of therapeutic strategies are urgently awaited.

In conclusion, the main finding in our analysis is the high rate of all major adverse outcomes of COVID-19 infection in hospitalized KTx recipients.

Supplementary Materials: The following are available online at http://www.mdpi.com/2077-0383/9/9/2986/s1, Supplementary Item S1: Search Strategy, Supplementary Item S2: PRISMA Checklist, Supplementary Item S3: Study Quality Assessment-JBI critical appraisal checklist for case series, Supplementary Item S4: Study Quality Assessment-JBI critical appraisal checklist for case reports.

Author Contributions: S.M. performed the design of the study, conducted the main literature search, wrote the manuscript, and supervised the work. K.G. contributed to the study design, conducted the main literature search, and participated in the writing of the "methods" section. M.K. and S.T. collected and analyzed data, did the statistics, and wrote the tables. I.B. and V.P. have reviewed and approved the final version of the manuscript. All authors have read and agreed to the published version of the manuscript.

Funding: This research received no external funding.

Acknowledgments: This review is dedicated to all transplanted patients who have lost their lives due to COVID-19 worldwide.

Conflicts of Interest: The authors declare no conflict of interest.

\section{References}

1. Sun, P.; Lu, X.; Xu, C.; Sun, W.; Pan, B. Understanding of COVID-19 based on current evidence. J. Med. Virol. 2020, 92, 548-551. [CrossRef] [PubMed]

2. Centers for Disease Control and Prevention. People with Underlying Medical Conditions, Immunocompromised State (Weakened Immune System) from Solid Organ Transplant. 2020. Available online: https: //www.cdc.gov/coronavirus/2019-ncov/need-extra-precautions/people-with-medical-conditions.html\# immunocompromised-state (accessed on 30 July 2020). 
3. Akalin, E.; Azzi, Y.; Bartash, R.; Seethamraju, H.; Parides, M.; Hemmige, V.; Ross, M.; Forest, S.; Goldstein, Y.D.; Ajaimy, M.; et al. Covid-19 and Kidney Transplantation. N. Engl. J. Med. 2020, 382, 2475-2477. [CrossRef] [PubMed]

4. Pereira, M.R.; Mohan, S.; Cohen, D.J.; Husain, S.A.; Dube, G.K.; Ratner, L.E.; Arcasoy, S.; Aversa, M.M.; Benvenuto, L.J.; Dadhania, D.M.; et al. COVID-19 in solid organ transplant recipients: Initial report from the US epicenter. Am. J. Transpl. 2020, 20, 1800-1808. [CrossRef] [PubMed]

5. Fishman, J.A. Infection in solid-organ transplant recipients. N. Engl. J. Med. 2007, 357, 2601-2614. [CrossRef] [PubMed]

6. Nair, V.; Jandovitz, N.; Hirsch, J.S.; Nair, G.; Abate, M.; Bhaskaran, M.; Grodstein, E.; Berlinrut, I.; Hirschwerk, D.; Cohen, S.L.; et al. COVID-19 in kidney transplant recipients. Am. J. Transpl. 2020, 20, 1819-1825. [CrossRef]

7. Alberici, F.; Delbarba, E.; Manenti, C.; Econimo, L.; Valerio, F.; Pola, A.; Maffei, C.; Possenti, S.; Zambetti, N.; Moscato, M.; et al. A single center observational study of the clinical characteristics and short-term outcome of 20 kidney transplant patients admitted for SARS-CoV2 pneumonia. Kidney Int. 2020, 97, 1083-1088. [CrossRef]

8. Moher, D.; Liberati, A.; Tetzlaff, J.; Altman, D.G. Preferred reporting items for systematic reviews and meta-analyses: The PRISMA statement. PLoS Med. 2009, 6, e1000097. [CrossRef]

9. Akdur, A.; Karakaya, E.; Ayvazoglu Soy, E.H.; Alshalabi, O.; Kirnap, M.; Arslan, H.; Ulubay, G.; Hekimoglu, K.; Moray, G.; Haberal, M. Coronavirus Disease (COVID-19) in Kidney and Liver Transplant Patients: A Single-Center Experience. Exp. Clin. Transpl. 2020, 18, 270-274. [CrossRef]

10. Allam, S.R.; Dao, A.; Madhrira, M.M.; Antiporta, P.B.; Nair, R.R.; Guiteau, J.J.; Reyad, A.I. Interleukin-6 receptor antagonist therapy to treat SARS-CoV-2 driven inflammatory syndrome in a kidney transplant recipient. Transpl. Infect. Dis. 2020, 22, e13326. [CrossRef]

11. Bartiromo, M.; Borchi, B.; Botta, A.; Bagalà, A.; Lugli, G.; Tilli, M.; Cavallo, A.; Xhaferi, B.; Cutruzzulà, R.; Vaglio, A.; et al. Threatening drug-drug interaction in a kidney transplant patient with coronavirus disease 2019 (COVID-19). Transpl. Infect. Dis. 2020, 22, e13286. [CrossRef]

12. Billah, M.; Santeusanio, A.; Delaney, V.; Cravedi, P.; Farouk, S.S. A catabolic state in a kidney transplant recipient with COVID-19. Transpl. Int. 2020. [CrossRef]

13. Bussalino, E.; De Maria, A.; Russo, R.; Paoletti, E. Immunosuppressive therapy maintenance in a kidney transplant recipient with SARS-CoV-2 pneumonia: A case report. Am. J. Transpl. 2020, 20, 1922-1924. [CrossRef] [PubMed]

14. Chen, S.; Yin, Q.; Shi, H.; Du, D.; Chang, S.; Ni, L.; Qiu, H.; Chen, Z.; Zhang, J.; Zhang, W. A familial cluster, including a kidney transplant recipient, of Coronavirus Disease 2019 (COVID-19) in Wuhan, China. Am. J. Transpl. 2020, 20, 1869-1874. [CrossRef] [PubMed]

15. Cheng, D.R.; Wen, J.Q.; Liu, Z.Z.; Lv, T.F.; Chen, J.S. Coronavirus disease 2019 in renal transplant recipients: Report of two cases. Transpl. Infect. Dis. 2020, e13329. [CrossRef] [PubMed]

16. Chenna, A.; Konala, V.M.; Gayam, V.; Naramala, S.; Adapa, S. Coronavirus Disease 2019 (COVID-19) in a Renal Transplant Patient. Cureus 2020, 12, e8038. [CrossRef]

17. Dirim, A.B.; Demir, E.; Ucar, A.R.; Garayeva, N.; Safak, S.; Oto, O.A.; Yazici, H.; Alibeyoglu, A.M.; Orhun, G.; Cagatay, A.A.; et al. Fatal SARS-CoV-2 infection in a renal transplant recipient. CEN Case Rep. 2020, 1-4. [CrossRef] [PubMed]

18. Fontana, F.; Alfano, G.; Mori, G.; Amurri, A.; Tei, L.; Ballestri, M.; Leonelli, M.; Facchini, F.; Damiano, F.; Magistroni, R.; et al. COVID-19 pneumonia in a kidney transplant recipient successfully treated with tocilizumab and hydroxychloroquine. Am. J. Transpl. 2020, 20, 1902-1906. [CrossRef]

19. Gandolfini, I.; Delsante, M.; Fiaccadori, E.; Zaza, G.; Manenti, L.; Degli Antoni, A.; Peruzzi, L.; Riella, L.V.; Cravedi, P.; Maggiore, U. COVID-19 in kidney transplant recipients. Am. J. Transpl. 2020, 20, 1941-1943. [CrossRef]

20. Guillen, E.; Pineiro, G.J.; Revuelta, I.; Rodriguez, D.; Bodro, M.; Moreno, A.; Campistol, J.M.; Diekmann, F.; Ventura-Aguiar, P. Case report of COVID-19 in a kidney transplant recipient: Does immunosuppression alter the clinical presentation? Am. J. Transpl. 2020, 20, 1875-1878. [CrossRef]

21. Hasan Ahmad, S.; Smith, R.; Camilleri, B. Belatacept, kidney transplantation and COVID-19: Successful management of the first reported case within the United Kingdom. Clin. Transpl. 2020, e14026. [CrossRef] 
22. Hsu, J.J.; Gaynor, P.; Kamath, M.; Fan, A.; Al-Saffar, F.; Cruz, D.; Nsair, A. COVID-19 in a high-risk dual heart and kidney transplant recipient. Am. J. Transpl. 2020, 20, 1911-1915. [CrossRef]

23. Huang, J.; Lin, H.; Wu, Y.; Fang, Y.; Kumar, R.; Chen, G.; Lin, S. COVID-19 in posttransplant patients-report of 2 cases. Am. J. Transpl. 2020, 20, 1879-1881. [CrossRef] [PubMed]

24. Jiang, J.; Miao, Y.; Zhao, Y.; Lu, X.; Zhou, P.; Zhou, X.; Chen, Z.; Du, D. Convalescent Plasma Therapy: Helpful Treatment of COVID-19 in a Kidney Transplant Recipient presenting with serve clinical manifestation and complex complications. Clin. Transpl. 2020, e14025. [CrossRef]

25. Kates, O.S.; Fisher, C.E.; Stankiewicz-Karita, H.C.; Shepherd, A.K.; Church, E.C.; Kapnadak, S.G.; Lease, E.D.; Riedo, F.X.; Rakita, R.M.; Limaye, A.P. Earliest cases of coronavirus disease 2019 (COVID-19) identified in solid organ transplant recipients in the United States. Am. J. Transpl. 2020, 20, 1885-1890. [CrossRef] [PubMed]

26. Kemmner, S.; Guba, M.O.; Schönermarck, U.; Stangl, M.; Fischereder, M. Cyclosporine as a preferred calcineurin inhibitor in renal allograft recipients with COVID-19 infection. Kidney Int. 2020, 98, 507-508. [CrossRef]

27. Kim, Y.; Kwon, O.; Paek, J.H.; Park, W.Y.; Jin, K.; Hyun, M.; Lee, J.Y.; Kim, H.A.; Han, S. Two distinct cases with COVID-19 in kidney transplant recipients. Am. J. Transpl. 2020. [CrossRef]

28. Kocak, B.; Arpali, E.; Akyollu, B.; Yelken, B.; Tekin, S.; Kanbay, M.; Turkmen, A.; Kalayoglu, M. A Case Report of Oligosymptomatic Kidney Transplant Patients with COVID-19: Do They Pose a Risk to Other Recipients? Transpl. Proc. 2020. [CrossRef] [PubMed]

29. Kolonko, A.; Dudzicz, S.; Wiecek, A.; Król, R. COVID-19 infection in solid organ transplant recipients: A single-center experience with patients immediately after transplantation. Transpl. Infect. Dis. 2020, e13381. [CrossRef]

30. Kumar, R.N.; Tanna, S.D.; Shetty, A.A.; Stosor, V. COVID-19 in an HIV-positive Kidney Transplant Recipient. Transpl. Infect. Dis. 2020, e13338. [CrossRef]

31. Lauterio, A.; Valsecchi, M.; Santambrogio, S.; De Carlis, R.; Merli, M.; Calini, A.; Centonze, L.; Buscemi, V.; Bottiroli, M.; Puoti, M.; et al. Successful recovery from severe COVID-19 pneumonia after kidney transplantation: The interplay between immunosuppression and novel therapy including tocilizumab. Transpl. Infect. Dis. 2020, e13334. [CrossRef]

32. Machado, D.J.B.; Ianhez, L.E. COVID-19 pneumonia in kidney transplant recipients-Where we are? Transpl. Infect. Dis. 2020, e13306. [CrossRef]

33. Man, Z.; Jing, Z.; Huibo, S.; Bin, L.; Fanjun, Z. Viral shedding prolongation in a kidney transplant patient with COVID-19 pneumonia. Am. J. Transpl. 2020. [CrossRef] [PubMed]

34. Marx, D.; Moulin, B.; Fafi-Kremer, S.; Benotmane, I.; Gautier, G.; Perrin, P.; Caillard, S. First case of COVID-19 in a kidney transplant recipient treated with belatacept. Am. J. Transpl. 2020, 20, 1944-1946. [CrossRef]

35. Meziyerh, S.; Zwart, T.C.; van Etten, R.W.; Janson, J.A.; van Gelder, T.; Alwayn, I.P.J.; de Fijter, J.W.; Reinders, M.E.J.; Moes, D.; de Vries, A.P.J. Severe COVID-19 in a renal transplant recipient: A focus on pharmacokinetics. Am. J. Transpl. 2020, 20, 1896-1901. [CrossRef] [PubMed]

36. Namazee, N.; Mahmoudi, H.; Afzal, P.; Ghaffari, S. Novel Corona Virus 2019 pneumonia in a kidney transplant recipient. Am. J. Transpl. 2020. [CrossRef] [PubMed]

37. Ning, L.; Liu, L.; Li, W.; Liu, H.; Wang, J.; Yao, Z.; Zhang, S.; Zhao, D.; Nashan, B.; Shen, A.; et al. Novel coronavirus (SARS-CoV-2) infection in a renal transplant recipient: Case report. Am. J. Transpl. 2020, 20, 1864-1868. [CrossRef]

38. Seminari, E.; Colaneri, M.; Sambo, M.; Gallazzi, I.; Di Matteo, A.; Roda, S.; Bruno, R. SARS Cov-2 infection in a renal-transplanted patient: A case report. Am. J. Transpl. 2020, 20, 1882-1884. [CrossRef]

39. Serrano, O.K.; Kutzler, H.L.; Rochon, C.; Radojevic, J.A.; Lawlor, M.T.; Hammond, J.A.; Gluck, J.; Feingold, A.D.; Jaiswal, A. Incidental COVID-19 in a heart-kidney transplant recipient with malnutrition and recurrent infections: Implications for the SARS-CoV-2 immune response. Transpl. Infect. Dis. 2020, e13367. [CrossRef]

40. Shingare, A.; Bahadur, M.M.; Raina, S. COVID-19 in recent kidney transplant recipients. Am. J. Transpl. 2020. [CrossRef]

41. Antony, S.J.; Singh, J.; de Jesus, M.; Lance, J. Early Use of Tocilizumab in Respiratory Failure Associated with Acute COVID-19 Pneumonia in Recipients with Solid Organ Transplantation. IDCases 2020, e00888. [CrossRef] 
42. Suwanwongse, K.; Shabarek, N. Fatal Outcome in a Kidney-Pancreas Transplant Recipient With COVID-19. Cureus 2020, 12. [CrossRef] [PubMed]

43. Tantisattamo, E.; Reddy, U.G.; Duong, D.K.; Ferrey, A.J.; Ichii, H.; Dafoe, D.C.; Kalantar-Zadeh, K. Hyponatremia: A Possible Immuno-Neuroendocrine Interface with COVID-19 in a Kidney Transplant Recipient. Transpl. Infect. Dis. 2020, e13355. [CrossRef]

44. Thammathiwat, T.; Tungsanga, S.; Tiankanon, K.; Torvorapanit, P.; Chumpangern, W.; Udomkarnjananun, S.; Avihingsanon, Y.; Sriprasart, T.; Srisawat, N.; Jutivorakool, K.; et al. A Case of Successful Treatment of Severe COVID-19 Pneumonia with Favipiravir and Tocilizumab in Post-kidney Transplant Recipient. Transpl. Infect. Dis. 2020, e13388. [CrossRef]

45. Velioglu, A.; Tuglular, S. Care of Asymptomatic SARS-CoV-2 positive Kidney Transplant Recipients. Transpl. Int. 2020. [CrossRef] [PubMed]

46. Wang, J.; Li, X.; Cao, G.; Wu, X.; Wang, Z.; Yan, T. COVID-19 in a Kidney Transplant Patient. Eur. Urol. 2020, 77, 769-770. [CrossRef]

47. Xia, T.; Wang, Y. Coronavirus disease 2019 and transplantation: The combination of lopinavir/ritonavir and hydroxychloroquine is responsible for excessive tacrolimus trough level and unfavorable outcome. Am. J. Transpl. 2020. [CrossRef]

48. Xu, J.J.; Samaha, D.; Mondhe, S.; Massicotte-Azarniouch, D.; Knoll, G.; Ruzicka, M. Renal infarct in a COVID-19-positive kidney-pancreas transplant recipient. Am. J. Transpl. 2020. [CrossRef]

49. Zhong, Z.; Zhang, Q.; Xia, H.; Wang, A.; Liang, W.; Zhou, W.; Zhou, L.; Liu, X.; Rao, L.; Li, Z.; et al. Clinical characteristics and immunosuppressant management of coronavirus disease 2019 in solid organ transplant recipients. Am. J. Transpl. 2020, 20, 1916-1921. [CrossRef]

50. Abrishami, A.; Samavat, S.; Behnam, B.; Arab-Ahmadi, M.; Nafar, M.; Sanei Taheri, M. Clinical Course, Imaging Features, and Outcomes of COVID-19 in Kidney Transplant Recipients. Eur. Urol. 2020, 78, 281-286. [CrossRef]

51. Banerjee, D.; Popoola, J.; Shah, S.; Ster, I.C.; Quan, V.; Phanish, M. COVID-19 infection in kidney transplant recipients. Kidney Int. 2020, 97, 1076-1082. [CrossRef]

52. Bösch, F.; Börner, N.; Kemmner, S.; Lampert, C.; Jacob, S.; Koliogiannis, D.; Stangl, M.; Michel, S.; Kneidinger, N.; Schneider, C.; et al. Attenuated early inflammatory response in solid organ recipients with COVID-19. Clin. Transpl. 2020, e14027. [CrossRef]

53. Bossini, N.; Alberici, F.; Delbarba, E.; Valerio, F.; Manenti, C.; Possenti, S.; Econimo, L.; Maffei, C.; Pola, A.; Terlizzi, V.; et al. Kidney transplant patients with SARS-CoV-2 infection: The brescia renal COVID task force experience. Am. J. Transpl. 2020. [CrossRef] [PubMed]

54. Chen, T.Y.; Farghaly, S.; Cham, S.; Tatem, L.L.; Sin, J.H.; Rauda, R.; Ribisi, M.; Sumrani, N. COVID-19 pneumonia in kidney transplant recipients: Focus on immunosuppression management. Transpl. Infect. Dis. 2020, e13378. [CrossRef]

55. University, C. Early Description of Coronavirus 2019 Disease in Kidney Transplant Recipients in New York. J. Am. Soc. Nephrol. 2020, 31, 1150-1156. [CrossRef]

56. Crespo, M.; Pérez-Sáez, M.J.; Redondo-Pachón, D.; Llinàs-Mallol, L.; Montero, M.M.; Villar-García, J.; Arias-Cabrales, C.; Buxeda, A.; Burballa, C.; Vázquez, S.; et al. COVID-19 in elderly kidney transplant recipients. Am. J. Transpl. 2020. [CrossRef] [PubMed]

57. Devresse, A.; Belkhir, L.; Vo, B.; Ghaye, B.; Scohy, A.; Kabamba, B.; Goffin, E.; De Greef, J.; Mourad, M.; De Meyer, M.; et al. COVID-19 Infection in Kidney Transplant Recipients: A Single-Center Case Series of 22 Cases From Belgium. Kidney Med. 2020. [CrossRef]

58. Fernández-Ruiz, M.; Andrés, A.; Loinaz, C.; Delgado, J.F.; López-Medrano, F.; San Juan, R.; González, E.; Polanco, N.; Folgueira, M.D.; Lalueza, A.; et al. COVID-19 in solid organ transplant recipients: A single-center case series from Spain. Am. J. Transpl. 2020, 20, 1849-1858. [CrossRef] [PubMed]

59. Fung, M.; Chiu, C.Y.; DeVoe, C.; Doernberg, S.B.; Schwartz, B.S.; Langelier, C.; Henrich, T.J.; Yokoe, D.; Davis, J.; Hays, S.R.; et al. Clinical outcomes and serologic response in solid organ transplant recipients with COVID-19: A case series from the United States. Am. J. Transpl. 2020. [CrossRef]

60. Maritati, F.; Cerutti, E.; Zuccatosta, L.; Fiorentini, A.; Finale, C.; Ficosecco, M.; Cristiano, F.; Capestro, A.; Balestra, E.; Taruscia, D.; et al. SARS-CoV-2 infection in kidney transplant recipients: Experience of the italian marche region. Transpl. Infect. Dis. 2020, e13377. [CrossRef] 
61. Mehta, S.A.; Leonard, J.; Labella, P.; Cartiera, K.; Soomro, I.; Neumann, H.; Montgomery, R.A.; Ali, N.M. Outpatient management of kidney transplant recipients with suspected COVID-19-Single-center experience during the New York City surge. Transpl. Infect. Dis. 2020, e13383. [CrossRef]

62. Mella, A.; Mingozzi, S.; Gallo, E.; Lavacca, A.; Rossetti, M.; Clari, R.; Randone, O.; Maffei, S.; Salomone, M.; Imperiale, D.; et al. Case series of six kidney transplanted patients with COVID-19 pneumonia treated with tocilizumab. Transpl. Infect. Dis. 2020, e13348. [CrossRef]

63. Montagud-Marrahi, E.; Cofan, F.; Torregrosa, J.V.; Cucchiari, D.; Ventura-Aguiar, P.; Revuelta, I.; Bodro, M.; Piñeiro, G.J.; Esforzado, N.; Ugalde, J.; et al. Preliminary data on outcomes of SARS-CoV-2 infection in a Spanish single center cohort of kidney recipients. Am. J. Transpl. 2020. [CrossRef] [PubMed]

64. Rodriguez-Cubillo, B.; Moreno de la Higuera, M.A.; Lucena, R.; Valdes Franci, E.; Hurtado, M.; Calvo Romero, N.; Rodriguez Moreno, A.; Valencia, D.; Velo, M.; Sagastagoitia Fornie, I.; et al. Should cyclosporine be useful in renal transplant recipients affected by SARS-CoV-2? Am. J. Transpl. 2020. [CrossRef] [PubMed]

65. Silva, F.; Cipriano, A.; Cruz, H.; Tavares, J.; Fragoso, J.; Malheiro, J.; Almeida, M.; Martins, S.; Abreu, M.; Pedroso, S.; et al. SARS-CoV-2 infection in kidney transplant recipients: Early report of five cases. Transpl. Infect. Dis. 2020, e13394. [CrossRef]

66. Trujillo, H.; Caravaca-Fontán, F.; Sevillano, Á.; Gutiérrez, E.; Caro, J.; Yuste, C.; Andrés, A.; Praga, M. SARS-CoV-2 Infection in Hospitalized Patients with Kidney Disease. Kidney Int. Rep. 2020, 5, $905-909$. [CrossRef] [PubMed]

67. Zhang, H.; Dai, H.; Xie, X. Solid Organ Transplantation During the COVID-19 Pandemic. Front. Immunol. 2020, 11, 1392. [CrossRef] [PubMed]

68. Zhu, L.; Gong, N.; Liu, B.; Lu, X.; Chen, D.; Chen, S.; Shu, H.; Ma, K.; Xu, X.; Guo, Z.; et al. Coronavirus Disease 2019 Pneumonia in Immunosuppressed Renal Transplant Recipients: A Summary of 10 Confirmed Cases in Wuhan, China. Eur. Urol. 2020, 77, 748-754. [CrossRef]

69. Imam, A.; Abukhalaf, S.A.; Imam, R.; Abu-Gazala, S.; Merhav, H.; Khalaileh, A. Kidney Transplantation in the Times of COVID-19-A Literature Review. Ann. Transpl. 2020, 25, e925755. [CrossRef]

70. Esagian, S.M.; Ziogas, I.A.; Giannis, D.; Hayat, M.H.; Elias, N.; Tsoulfas, G. Challenges in Abdominal Organ Transplantation During the COVID-19 Pandemic. Front. Med. 2020, 7, 287. [CrossRef]

71. Husain, S.A.; Dube, G.; Morris, H.; Fernandez, H.; Chang, J.H.; Paget, K.; Sritharan, S.; Patel, S.; Pawliczak, O.; Boehler, M.; et al. Early Outcomes of Outpatient Management of Kidney Transplant Recipients with Coronavirus Disease 2019. Clin. J. Am. Soc. Nephrol. 2020. [CrossRef]

72. D'Antiga, L. Coronaviruses and Immunosuppressed Patients: The Facts During the Third Epidemic. Liver Transplant. 2020, 26, 832-834. [CrossRef] [PubMed]

73. Zhou, F.; Yu, T.; Du, R.; Fan, G.; Liu, Y.; Liu, Z.; Xiang, J.; Wang, Y.; Song, B.; Gu, X.; et al. Clinical course and risk factors for mortality of adult inpatients with COVID-19 in Wuhan, China: A retrospective cohort study. Lancet 2020, 395, 1054-1062. [CrossRef]

74. Garg, S.; Kim, L.; Whitaker, M.; O’Halloran, A.; Cummings, C.; Holstein, R.; Prill, M.; Chai, S.J.; Kirley, P.D.; Alden, N.B.; et al. Hospitalization Rates and Characteristics of Patients Hospitalized with Laboratory-Confirmed Coronavirus Disease 2019_COVID-NET, 14 States, 1-30 March 2020. MMWR Morb. Mortal. Wkly. Rep. 2020, 69, 458-464. [CrossRef]

75. Lighter, J.; Phillips, M.; Hochman, S.; Sterling, S.; Johnson, D.; Francois, F.; Stachel, A. Obesity in Patients Younger Than 60 Years Is a Risk Factor for COVID-19 Hospital Admission. Clin. Infect. Dis. 2020, 71, 896-897. [CrossRef]

76. Johns Hopkins Coronavirus Resource Center. Available online: https://coronavirus.jhu.edu/map.html (accessed on 6 September 2020).

77. Yang, X.; Yu, Y.; Xu, J.; Shu, H.; Xia, J.; Liu, H.; Wu, Y.; Zhang, L.; Yu, Z.; Fang, M.; et al. Clinical course and outcomes of critically ill patients with SARS-CoV-2 pneumonia in Wuhan, China: A single-centered, retrospective, observational study. Lancet Respir. Med. 2020, 8, 475-481. [CrossRef]

78. Chu, K.H.; Tsang, W.K.; Tang, C.S.; Lam, M.F.; Lai, F.M.; To, K.F.; Fung, K.S.; Tang, H.L.; Yan, W.W.; Chan, H.W.; et al. Acute renal impairment in coronavirus-associated severe acute respiratory syndrome. Kidney Int. 2005, 67, 698-705. [CrossRef] [PubMed]

79. Tisoncik, J.R.; Korth, M.J.; Simmons, C.P.; Farrar, R.J.; Martin, T.; Katze, M.G. Into the Eye of the Cytokine Storm. Microbiol. Mol. Biol. Rev. 2012, 76, 16-32. [CrossRef] 
80. Mombelli, M.; Kampouri, E.; Manuel, O. Influenza in solid organ transplant recipients: Epidemiology, management, and outcomes. Expert Rev. Anti-Infect. Ther. 2020, 18, 103-112. [CrossRef]

81. Ritter, M.L.; Pirofski, L. Mycophenolate mofetil: Effects on cellular immune subsets, infectious complications, and antimicrobial activity. Transpl. Infect. Dis. 2009, 11, 290-297. [CrossRef]

82. Berger, S.P.; Sommerer, C.; Witzke, O.; Tedesco, H.; Chadban, S.; Mulgaonkar, S.; Qazi, Y.; de Fijter, J.W.; Oppenheimer, F.; Cruzado, J.M.; et al. Two-year outcomes in de novo renal transplant recipients receiving everolimus-facilitated calcineurin inhibitor reduction regimen from the TRANSFORM study. Am. J. Transpl. 2019, 19, 3018-3034. [CrossRef]

83. Zaza, G.; Granata, S.; Tomei, P.; Masola, V.; Gambaro, G.; Lupo, A. mTOR inhibitors and renal allograft: Yin and Yang. J. Nephrol. 2014, 27, 495-506. [CrossRef] [PubMed]

84. Marfo, K.; Greenstein, S. Antiretroviral and immunosuppressive drug-drug interactions in human immunodeficiency virus-infected liver and kidney transplant recipients. Transpl. Proc. 2009, 41, 3796-3799. [CrossRef] [PubMed]

85. Chen, C.Y.; Wang, F.L.; Lin, C.C. Chronic hydroxychloroquine use associated with QT prolongation and refractory ventricular arrhythmia. Clin. Toxicol. 2006, 44, 173-175. [CrossRef] [PubMed]

86. Warren, T.K.; Jordan, R.; Lo, M.K.; Ray, A.S.; Mackman, R.L.; Soloveva, V.; Siegel, D.; Perron, M.; Bannister, R.; Hui, H.C.; et al. Therapeutic efficacy of the small molecule GS-5734 against Ebola virus in rhesus monkeys. Nature 2016, 531, 381-385. [CrossRef] [PubMed]

87. Beigel, J.H.; Tomashek, K.M.; Dodd, L.E.; Mehta, A.K.; Zingman, B.S.; Kalil, A.C.; Hohmann, E.; Chu, H.Y.; Luetkemeyer, A.; Kline, S.; et al. Remdesivir for the Treatment of Covid-19-Preliminary Report. N. Engl. J. Med. 2020. [CrossRef] [PubMed]

88. Gautret, P.; Lagier, J.C.; Parola, P.; Hoang, V.T.; Meddeb, L.; Mailhe, M.; Doudier, B.; Courjon, J.; Giordanengo, V.; Vieira, V.E.; et al. Hydroxychloroquine and azithromycin as a treatment of COVID-19: Results of an open-label non-randomized clinical trial. Int. J. Antimicrob. Agents 2020, 56, 105949. [CrossRef]

89. WHO. Discontinues Hydroxychloroquine and Lopinavir/Ritonavir Treatment Arms for COVID-19. Published online 4 July 2020; WHO Website. 2020. Available online: https://www.who.int/news-room/detail/04-07-2020who-discontinues-hydroxychloroquine-and-lopinavir-/ritonavir-treatment-arms-for-covid-19 (accessed on 30 July 2020).

90. Shang, L.; Zhao, J.; Hu, Y.; Du, R.; Cao, B. On the use of corticosteroids for 2019-nCoV pneumonia. Lancet 2020, 395, 683-684. [CrossRef]

91. Horby, P.; Lim, W.S.; Emberson, J.R.; Mafham, M.; Bell, J.L.; Linsell, L.; Staplin, N.; Brightling, C.; Ustianowski, A.; Elmahi, E.; et al. Dexamethasone in Hospitalized Patients with Covid-19_Preliminary Report. N. Engl. J. Med. 2020. [CrossRef]

92. Frey, N.; Porter, D. Cytokine Release Syndrome with Chimeric Antigen Receptor T Cell Therapy. Biol. Blood Marrow Transpl. 2019, 25, e123-e127. [CrossRef] 